\title{
Prevalence of old age hypertension and associated factors among older adults in rural Ethiopia
}

This article was published in the following Dove Press journal:

Integrated Blood Pressure Control

\author{
Arif Shukuri ${ }^{1}$ \\ Tsegaye Tewelde (iD) ${ }^{2}$ \\ Tamrat Shaweno ${ }^{2}$ \\ 'Disease Prevention and Control, West \\ Hararge Zonal Health Department, \\ Harar, Ethiopia; ${ }^{2}$ Department of \\ Epidemiology, Faculty of Public Health, \\ Jimma University Institute of Health, \\ Jimma, Ethiopia
}

Background: Older adults are disproportionately affected by hypertension, which is an established risk factor for cardiovascular disease. Despite these facts, little information is available with regard to old age hypertension in Ethiopia. Thus, this study assessed old age hypertension and associated factors among older adults in rural Ethiopia.

Methods: A community-based cross-sectional study design was employed among 418 selected permanent residents of Chiro town aged 50 years and older using simple random sampling technique. Data were collected face to face using a structured questionnaire which is adapted from the WHO Stepwise approach to surveillance of non communicable disease instrument, and was used to collect data on risk factors. Physical measurements were taken as per WHO STEP guidelines. The data were entered into Epi Data version 3.1 and exported to SPSS Version 20 for analysis. Bivariate and multivariable logistic regression analysis were conducted and statistical significance was declared at a $p$-value $\leq 0.05$.

Results: The overall prevalence of old age hypertension was $41.9 \%$ (95\% CI: 37.2-46.6). Age $\geq 70$ years (AOR: 1.91; 95\% CI: 1.12-3.27), low intake of fruits (AOR: $2.45 ; 95 \% \mathrm{CI}$ : 1.55-3.86), overweight/obese (AOR: 4.29 ; 95\% CI: 2.48-7.42) and family history of hypertension (AOR: 2.95; 95\% CI: 1.70-5.12) were significantly associated risk factors of hypertension.

Conclusion: The prevalence of hypertension among older adults was high. Older age $\geq 70$ years, low intake of fruits, overweight/obese and having a family history of hypertension were significantly associated with hypertension. Consideration should be given for community-based screening of hypertension among older adults. In addition, fruit consumption habits and maintaining normal weight should be encouraged.

Keywords: old age hypertension, prevalence, Ethiopia

\section{Introduction}

Chronic non-communicable diseases (CNCDs) in general and hypertension in particular were originally thought to be associated with affluent societies. Contrary to the common perception of relating CNCDs to the developed world, an epidemiologic shift has given rise to an increase in hypertension and other CNCDs in developing countries. ${ }^{1}$ Hypertension is defined as systolic blood pressure (SBP) persistently $\geq 140$ and/or diastolic blood pressure (DBP) $\geq 90 \mathrm{mmHg}$ and/or taking an anti-hypertensive drug. ${ }^{2}$ An elevation of the systolic and/or diastolic blood pressure increases the risk of developing heart disease, kidney disease, hardening of the arteries, eye damage, and stroke., Hypertensive symptoms that may occur include chest pain, confusion, ear buzzing, irregular heartbeat, nosebleed, tiredness, headache and vision changes. ${ }^{5}$ For this reason, the routine screening of symptomatic individuals is critical in the early diagnosis, treatment and control of high blood pressure. ${ }^{6}$
Correspondence: Tamrat Shaweno Jimma University Institute of Health, P.O. Box 378, Jimma, Ethiopia

Tel +25I 912493482

Email babiynos@gmail.com 
Populations around the world are rapidly aging. By 2050 , around 2 billion people in the world will be aged 60 years and over, with 400 million aged 80 years and over. Of these older people, $80 \%$ will live in low- and middle-income countries (LMICs). The majority of older people die of NCDs such as hypertension, heart disease, cancer and diabetes, rather than from infectious and parasitic diseases. In addition, they often suffer from several health problems at the same time. Older people also experience higher rates of disability, reflecting an accumulation of health issues throughout their lives. ${ }^{7}$ Hypertension is one of the leading causes of mortality worldwide. The WHO's 2016 Global Health Observatory (GHO) data estimated that high blood pressure would cause 7.5 million deaths annually, about $12.8 \%$ of the total of all deaths. This accounts for 57 million disability-adjusted life years (DALYS) or 3.7\% of total DALYS. ${ }^{8}$ Hypertension is responsible for at least $45 \%$ of global deaths due to heart disease and $51 \%$ of deaths due to stroke. ${ }^{9}$

The global prevalence of hypertension in adults aged 18 years and above was around $22 \%$ in 2014 . Across the WHO regions, Africa has the highest prevalence of high blood pressure with $30 \%$ of the people affected, while the lowest was recorded in the American Region. ${ }^{10}$ The mean blood pressure levels in sub-Saharan Africa (SSA) increased significantly between 1975 and 2015 to levels that are among the highest in the world. ${ }^{11}$ A recent systematic review estimated that the pooled prevalence of hypertension in adults aged 65+ years in SSA was $61.0 \%{ }^{12}$ An epidemiological model showed that the pooled prevalence of hypertension in Africa in the elderly ranges from two to four times more than that in people aged 40 years or younger. ${ }^{13}$

Ethiopia is also one of the most affected countries in the region. According to a study conducted in Gondar City, Ethiopia the prevalence of hypertension in adults aged 18 years and above was $28.3 \%{ }^{14}$ Another study conducted in Durame town also indicated that the prevalence of hypertension in individuals 31 years of age and older was $22.4 \%$. In this study, the prevalence of hypertension was higher in older ages. For instance, the age wise distribution of hypertension increased from ages 31-40 $(2.9 \%)$, followed by the age group of $41-50$ years $(15.8 \%)$, and then $>50$ years $(52.6 \%){ }^{15}$

The new epidemic of hypertension and cardiovascular diseases is not only an important public health problem, but it will also have a big economic impact as a significant proportion of the productive population becomes chronically ill or dies, leaving their families in poverty. ${ }^{16}$ The increasing prevalence of hypertension has been attributed to population growth, aging and behavioral risk factors such as lack of physical activity, unhealthy diet, harmful use of alcohol and tobacco use. The risk factors also include overweight, obesity and diabetes mellitus. The adverse health consequences of hypertension are compounded because many people affected also have other health risk factors that increase the odds of heart attack, stroke, and kidney failure. It is not often appreciated that hypertension is preventable even in old age through lifestyle change. For example, promoting light or moderate physical activity has been shown to reduce mortality and heart attacks in older men., ${ }^{2,17}$

Hypertension has become a major public health problem especially in developing countries. Older adults are disproportionately affected by hypertension, which is an established risk factor for cardiovascular disease. Despite these facts, little attention has been focused on hypertension and associated factors among older adults in Africa. Moreover, the relatively limited available information on hypertension may lead to an increasing prevalence as well as poor detection, treatment and control rates. ${ }^{18}$

To our knowledge, there are no published studies regarding the prevalence and associated risk factors of hypertension among people aged 50 years and older in Ethiopia. Most research in this geographic area was conducted among the general adult population and non-specific to this age group. Whereas, some studies excluded those older adults who are at higher risk of NCDs. Restricting our studies toward the older age group will provide better information relating to this age group. Therefore, this study was aimed to determine the prevalence of hypertension and its associated factors among older adults in Chiro town.

\section{Materials and methods}

\section{Study area, design and period}

We conducted a community-based cross sectional study among adults aged 50 years and above residing in Chiro town which is located in the Eastern part of Ethiopia, 326 kilometers from the capital Addis Ababa. The town administration has three Kebeles (the smallest administrative unit in Ethiopia). According to the 2007 report of the Central Statistical Agency of Ethiopia, the projected total population of the town was $51,616(26,324$ are males, 
25,292 are females). There were 10,753 households and 5,832 older adults (aged 50 years and above) residing in the town. The town has one general hospital, one health center and seven medium-sized clinics. In most of them, the health care providers were nurses, health officers and rarely general practitioners. Data were collected from March 1-26, 2018.

\section{Sample size determination and sampling technique}

The sample size was calculated using Epi-info version 7 statistical software using the single population proportion formula. The prevalence of hypertension among adults aged 50 years and above was $44.9 \%$ taken from a study conducted in Banepa municipality, Nepal. ${ }^{19}$ Assuming $95 \%$ confidence level, $5 \%$ margin of error and $10 \%$ nonresponse rate, the final calculated sample size was 418 . The sample size for associated factors with hypertension was also calculated for the two population proportions formula by considering confidence level of $95 \%$, power of $80 \%$, prevalence of hypertension among participants who consume adequate vegetables $(\mathrm{P} 1=14.1)$ and prevalence of hypertension among participants who consume inadequate vegetables $\mathrm{P} 2=27.8$ ). From the previous other studies $^{14,15,20}$ conducted so far, inadequate intake of vegetables gave the sample size of 334 , even lower than the sample size calculated using single population proportion. Therefore, the larger sample size of 418 was used in this study.

With regard to sampling procedures, all the three kebeles in the town were selected for this study to get the representative sample of population. To develop the sampling frame complete census was done to get a list of all households with older adults aged 50 years and above in the town (4,284 households). Thus, the total sample size was allocated to each kebele based on proportional to size allocation. A total of 418 older adults were selected from an existing list of all those aged 50 years and above in the town using simple random sampling techniques (computer-generated random numbers). When there is more than one eligible older adult in the household, only one individual was selected randomly. During data collection if the eligible older adult was absent from the house, the household was revisited at least three times and an elder who was absent at the third visit was considered as a nonrespondent.

\section{Variables and measurement}

The major outcome variable was hypertension status. Predictor variables recorded included; age, sex, marital status, educational status, occupational status, monthly family income, physical activity, alcohol consumption, smoking cigarette, chewing khat, fruit and vegetable intake, central obesity and self-reported diabetes mellitus and family history of hypertension.

\section{Physical measurements Blood pressure}

Blood pressure was measured using a digital BP monitor (Omron M4). The study participants were allowed to rest (relax) with the legs uncrossed and insure no smoking or caffeine 30 minutes before measurement. The participant was positioned in such a way that the left upper arm was at the same level as the heart. Then three blood pressure measurements were taken 5 minutes apart in a sitting position. Finally, the mean of the second and the third $\mathrm{BP}$ readings were taken to determine the BP status of the participant. $^{21}$

\section{Weight, height, waist and hip circumference}

Weight of the older adults was measured to the nearest 0.1 $\mathrm{kg}$ by digital balance and height to the nearest $0.1 \mathrm{~cm}$ in the standing position with no shoes using a portable height board. Weight measuring scale was checked and adjusted at zero level between each measurement and was tested for repeatability of the measures. Body mass index (BMI) of respondents was calculated as weight in $\mathrm{kg}$ divided by height in meters squared and used to determine obesity and overweight. Waist circumference is also a widely recognized measure used to identify those with a health risk from being overweight. Waist circumference was measured by trained interviewers using a constant tension tape at the end of a normal expiration, with the arms relaxed at the sides, under the midline of the participant's armpit, at the midpoint between the lower part of the last rib and the top of the hip. Hip circumference was also measured with the arms relaxed at the sides, at the maximum circumference over the buttocks. Both measurements were taken over light clothing after securing privacy of participants and the results were used to determine abdominal obesity (central adiposity) of participants. 


\section{Operational definitions}

We defined older adults as adults aged 50 years and above. Similarity, hypertension was defined as systolic blood pressure $\geq 140 \mathrm{mmHg}$ and/or diastolic blood pressure $\geq 90$ $\mathrm{mmHg}$ and/or reported use of anti-hypertensive medication. ${ }^{3}$ With regard to level of physical activity, older adults were considered active (during work, transport and recreation) if he/she was engaged in moderate-intensity physical activity for at least 150 minutes per week or in vigorous-intensity physical activity for at least 75 minutes per week, or an equivalent combination of moderate and vigorous intensity activity, whereas, they were considered physically inactive if he/she was engaged in moderateintensity physical activity for $<150$ minutes per week, or vigorous-intensity physical activity for $<75$ minutes per week. ${ }^{17}$ Fruit and vegetable intake was considered good if fruit and vegetables were consumed on 3 days and more per week; and low if fruit and vegetable intake was $<3$ days per week. ${ }^{22}$ One serving of fruit was considered to be one medium size piece of banana, orange or mango (half cup of fruit from juice) and one serving of vegetable was considered to be one bowl of raw green leafy vegetables or half cup of other vegetables (cooked or chopped raw). In this study, alcohol consumption was considered as excessive; if $>14$ standard drinks of beer or $>21$ shot of spirit/Areki Melekia or $>21$ can of Tella or $>21$ Birille of Tej or $>10$ glasses of wine for men or $>7$ bottles of standard drink of beer or $>10$ shot of spirit/Areki or $>10$ Tassa of Tella or $>10$ Birille of Tej or $>7$ glasses of wine for women per day. ${ }^{23,24}$ One standard drink of alcohol was one standard bottle of regular beer $(330 \mathrm{~mL})$, one single measure of spirit/Areki Melekia (30 mL), one medium size glass of wine $(120 \mathrm{~mL})$, one Tassa of Tella or one Birille of Tej.

With regard to smoking status; adults were considered current smokers (if they had smoked cigarettes during the last month), previous smokers (if they had smoked before but not in the past month), and never-smokers (if they hadn't smoked a single cigarette in their lifetime). The current smokers were also classified as light smokers (less than 10 cigarettes/day), moderate smokers (10-20 cigarettes/day), and heavy smokers ( $>20$ cigarettes/day).

Concerning chewing khat, they were classified as current chewers if they had chewed daily for the past month; previous chewers if they had chewed before but had not chewed in the past month and non-chewers if they had never chewed in their lives. Reported diabetics were recorded if a self-reported diabetic patient (told by health professional) or one using anti-diabetic medication at the time of data collection. ${ }^{14}$ Central obesities were calculated as waist circumference divided by hip circumference and having WHR $>1.00$ in males and $>0.85$ in females was interpreted as elevated; whereas, a WHR $\leq 1.00$ in males and $\leq 0.85$ in females was considered normal.

\section{Data collection techniques and procedures}

Data were collected by face-to-face interview technique and by physical measurements after obtaining written informed consent. Data collection instruments were adapted from WHO STEP instrument for NCD risk factors. ${ }^{23}$ Data were collect by questioner-administered interview and by taking physical measurements. The questionnaire included socio-demographic information, behavioral characteristics, biological risk factors and physical measurements. The scope of the present study was limited to questionnaire-based and physical measurements and does not include biochemical measurements.

Data collectors were five experienced senior clinical nurses, who were supervised by two senior health officers and the principal investigators. In addition, 1 week prior to data collection, training and practical demonstrations on interview techniques and measurement procedures were given to data collectors and supervisors for 2 days. The questionnaire and physical measurements were pre-tested on $5 \%$ of the study participants found outside of the study area and modifications were made based on these findings.

\section{Data quality control}

To ensure data quality, the questionnaire was originally prepared in English and translated into the local language Afan Oromo and back translated to English by another person to check for its consistency. Data quality was also ensured through training of data collectors, supervisors, and pre-testing of questionnaires, using appropriate standard techniques and recruiting professionals to each activity. Supervisors checked the data collection process on a daily basis. The principal investigator ensured the data completeness, accuracy and consistency by arranging a meeting with data collectors every day after completion of the daily data collection process. In order to minimize inter-observer bias that may occur during physical measurement, data collector performance was assessed against selected participants on a daily basis. 


\section{Data analysis procedures}

After ensuring data quality and checking missing values, and coding of questionnaires, data were entered into Epidata version 3.1 then transferred to SPSS Version 20 for analysis. Descriptive statistics including: frequency, percent, mean and standard deviation (SD) were used to summarize study variables and evaluate distribution of responses. Bivariate logistic regression was done for each independent variable against outcome variable to estimate the crude odds ratio. The candidate variables for the multivariate analysis were selected at a $p$-value of less than and equal to 0.25 . Multi-variable logistic regressions were used to assess the independent effect of different variables after simultaneously controlling for the effect of other factors. Multi-collinearity was also checked to see the linear correlation among the independent variables by using the Variance Inflation Factor (VIF) test, the Tolerance test, and values of the standard error. Hosmer-Lemeshow test was found to be insignificant ( $p$-value $=0.54$ ) and the omnibus test was significant ( $p$-value $<0.001)$ which indicates the model was fitted adequately. Odds ratios with $95 \%$ CI were estimated to identify the factors associated with hypertension. Level of statistical significance was declared at $p$ value $<0.05$.

\section{Results}

\section{Socio-demographic characteristics}

Out of 418 eligible older adults, 401 subjects participated in the study making a response rate of $96 \%$. Of which, the male to female gender ratio was almost equally represented in this study with a 1:1 ratio. The majority of the respondents, $148(36.9 \%)$, were in the age group of 70 years and above with the mean age of $65.51(\mathrm{SD} \pm 10.91)$ years, while, 208 (51.9\%) of them were Muslim in religion and 187 (46.6\%) were Oromo by ethnicity. Regarding their educational status more than half $213(53.1 \%)$ of them were unable to read and write, while only $53(13.2 \%)$ of them were holding a diploma and above (Table 1).

\section{Description of the behavioral-, biological- and family-related risk factors of the participants}

Concerning the study participant's lifestyle behavior, 77 $(19.2 \%)$ of them reported that they had drunk excess alcohol, whereas $176(43.9 \%)$ of the respondents had ever chewed khat, and, among them, 118 (67\%) were current khat chewers. Concerning dietary practice, 203
Table I Socio-demographic characteristics of older adults in Chiro Town, Oromia, Ethiopia, 2018, (N=40I)

\begin{tabular}{|l|l|l|}
\hline Variables & Category & Frequency n (\%) \\
\hline Age group (in years) & $50-59$ & $132(32.9)$ \\
& $60-69$ & $121(30.2)$ \\
& $70+$ & $148(36.9)$ \\
\hline Sex & Male & $195(48.6)$ \\
& Female & $206(51.4)$ \\
\hline Marital status & Married & $240(59.9)$ \\
& Single & $5(1.2)$ \\
& Separated & $77(19.2)$ \\
& Divorced & $30(7.5)$ \\
& Widowed & $49(12.2)$ \\
\hline Occupation status & Homemaker & $59(14.7)$ \\
& Farmer & $18(4.5)$ \\
& Unemployed & $132(32.9)$ \\
& Retired & $47(11.7)$ \\
& Merchant & $62(15.5)$ \\
& Daily laborer & $30(7.5)$ \\
& Governmental or & $53(13.2)$ \\
& NGO employee & \\
\hline Monthly family & $\leq 1000$ & $261(65.1)$ \\
income (in EBR) & $1000-2000$ & $100(24.9)$ \\
& $2001-3000$ & $26(6.5)$ \\
\hline & $>3000$ & \\
\hline
\end{tabular}

(50.6\%) of the study subjects ate fruit on less than 3 days a week, while 193 (48.1\%) of them ate vegetables $<3$ days per week. Of the total respondents included in this study, 113 (28.2\%) were physically active.

Out of 401 respondents, over three quarters $(76.81 \%)$ of them had a BMI $<25.0 \mathrm{~kg} / \mathrm{m}^{2}$ with a mean of 23.15 (SD $\pm 3.39 \mathrm{~kg} / \mathrm{m}^{2}$ ). Among the 93 (23.19\%) of those who had a BMI $\geq 25.0 \mathrm{~kg} / \mathrm{m}^{2}$, a higher proportion of them were women $52(25 \%)$ than men 41 (21\%). Concerning central obesity, 160 (39.9\%) had a high waist to hip circumference ratio. For a history of NCDs, 45 (11.2\%) of study participants were reported to have DM, while $88(21.9 \%)$ had reported a family history of hypertension (Table 2).

\section{Prevalence of hypertension}

The overall prevalence of hypertension was found to be 168 (41.9\% [95\% CI: 37.2-46.6]), while the mean of systolic and diastolic BP results were $126.24 \mathrm{mmHg}$ $( \pm 17.77 \mathrm{SD})$ and $78.26 \mathrm{mmHg}( \pm 11.60 \mathrm{SD})$ respectively. Among all hypertensive people identified, 144 (86\%) did not know they had hypertension (newly screened). The 
Table 2 Behavioral-, biological- and family-related characteristics among older adults in Chiro Town, Oromia, Ethiopia, March, $2018(\mathrm{~N}=40 \mathrm{I})$

\begin{tabular}{|c|c|c|}
\hline Variables & Category & Frequency n (\%) \\
\hline \multirow{2}{*}{ Physical activity } & Yes & $113(28.2)$ \\
\hline & No & $228(71.8)$ \\
\hline \multirow{2}{*}{$\begin{array}{l}\text { Excessive alcohol } \\
\text { consumption }\end{array}$} & Yes & 77 (19.2) \\
\hline & No & $324(80.8)$ \\
\hline \multirow[t]{3}{*}{ Cigarette smoking } & Never & $336(83.8)$ \\
\hline & Previous & $26(6.5)$ \\
\hline & Current & $39(9.7)$ \\
\hline \multirow[t]{3}{*}{ Chewing khat } & Never & $225(56.1)$ \\
\hline & Previous & $58(14.5)$ \\
\hline & Current & I I 8 (29.4) \\
\hline \multirow[t]{2}{*}{ Low intake of fruits } & Yes & $203(50.6)$ \\
\hline & No & $198(49.4)$ \\
\hline \multirow[t]{2}{*}{ Low intake of vegetables } & Yes & $193(48.1)$ \\
\hline & No & $208(51.9)$ \\
\hline \multirow[t]{3}{*}{ BMI } & Normal & $272(67.8)$ \\
\hline & Underweight & $36(9.0)$ \\
\hline & Overweight/obese & $93(23.2)$ \\
\hline \multirow[t]{2}{*}{ Waist to hip ratio } & Normal & $24 \mid(60.1)$ \\
\hline & Elevated & $160(39.9)$ \\
\hline \multirow[t]{2}{*}{ Self-reported DM } & Yes & $45(11.2)$ \\
\hline & No & $356(88.8)$ \\
\hline \multirow{2}{*}{$\begin{array}{l}\text { Family history of } \\
\text { hypertension }\end{array}$} & Yes & $88(21.9)$ \\
\hline & No & $313(78.1)$ \\
\hline
\end{tabular}

prevalence of hypertension in this study showed an increase with advancing age.

\section{Factors associated with hypertension}

Out of all independent variables entered into the bivariate logistic regression, older age 70 and above, physical inactivity, low intake of fruits, low intake of vegetables, overweight/obese and family history of hypertension were found to be significantly associated with hypertension (Table 3).

\section{Results of the multivariate analysis}

After adjusting for possible confounders in the multivariate logistic regression, being of older age, low intake of fruits, overweight/obese and having a family history of hypertension were found to be significantly associated with hypertension.
The likelihood of hypertension increased with advancing age. The age group 70 years and above were almost two times more likely to be hypertensive as compared to the 50 to 59 years of age group (AOR: 1.91; 95\% CI: 1.12-3.27). Older adults who eat fruit less than 3 days in their weekly menu were 2.45 times more likely to be hypertensive (AOR: 2.45 ; 95\% CI: $1.55-3.86)$ compared to those who eat fruit3 or more days per week. Being overweight/obese were four times (AOR: 4.29; 95\% CI: 2.48-7.42) more likely to be hypertensive compared to normal. Whereas, having a family history of hypertension had an almost three times (AOR: 2.95 ; 95\% CI: 1.70-5.12) greater risk of hypertension compared to their counterparts (Table 4).

\section{Discussion}

Older adults are disproportionately affected by hypertension, which is an established risk factor for cardiovascular disease. Despite these facts, in Ethiopia no study has been conducted on the prevalence and associated factors of hypertension among older adults.

In this study, the prevalence of hypertension was $41.9 \%$ (95\% CI: 37.2-46.6). This finding is consistent with crosssectional study conducted in Hohoe municipality, Ghana in 2017 which revealed that the prevalence of hypertension was $39.4 \%{ }^{25}$ It is also consistent with previous studies conducted in Banepa municipality, Nepal $(44.9 \%)^{19}$ and India $(42.7 \%){ }^{26}$ The prevalence of hypertension in the study area was much lower than previous studies conducted in Senegal and South Africa which showed that the prevalence of hypertension among adults aged 50 years and older were $65.4 \%$ and $77.3 \%$ respectively. ${ }^{26,27}$ This is possibly due to higher prevalence of overweight/obesity (72.4\% in South Africa and $53.8 \%$ in Senegal) when compared to the current study prevalence of only $23.19 \%$ ) and aging.

The finding of this study also revealed that the prevalence of hypertension in the study area was lower than the study conducted in different areas of the world. For example, a population-based cross-sectional study conducted in Miyun district of Beijing Chinese showed that the prevalence of hypertension in the community elderly was $53 \%{ }^{28}$ Another study conducted in Sao Paulo, Brazil among the elderly showed the prevalence of hypertension to be $46.7 \%{ }^{29}$ This difference might be due to the majority of participants being older.

The finding of the current study is consistent with the specific age group of the study conducted in Gondar among $\geq 55$ years (prevalence of $44 \%$ ). ${ }^{14}$ However, this finding is lower than studies conducted in Bedele town in 
Table 3 Results of the bivariate logistic regression analysis of factors associated with hypertension among older adults in Chiro Town, Oromia, Ethiopia, $2018(\mathrm{~N}=40 \mathrm{I})$

\begin{tabular}{|c|c|c|c|c|c|}
\hline \multirow[t]{2}{*}{ Variables } & \multirow[t]{2}{*}{ Category } & \multicolumn{2}{|c|}{ Hypertension n (\%) } & \multirow[t]{2}{*}{ COR $(95 \% \mathrm{Cl})$} & \multirow[t]{2}{*}{$p$-value } \\
\hline & & Yes & No & & \\
\hline Age group (in years) & $\begin{array}{l}50-59 \\
60-69 \\
70+\end{array}$ & $\begin{array}{l}43(32.6) \\
52(43.0) \\
73(49.3)\end{array}$ & $\begin{array}{l}89(67.4) \\
69(57.0) \\
75(50.7)\end{array}$ & $\begin{array}{l}\text { I } \\
1.56[0.94-2.60] \\
2.01[1.24-3.28]^{* *}\end{array}$ & 0.018 \\
\hline Physical activity & $\begin{array}{l}\text { Yes } \\
\text { No }\end{array}$ & $\begin{array}{l}37(32.7) \\
|3|(45.5)\end{array}$ & $\begin{array}{l}76(67.3) \\
157(54.5)\end{array}$ & I.7। $[1.09-2.75]^{*}$ & 0.021 \\
\hline Low intake of fruits & $\begin{array}{l}\text { Yes } \\
\text { No }\end{array}$ & $\begin{array}{l}10652.2) \\
62(31.3)\end{array}$ & $\begin{array}{l}97(47.8) \\
136(68.7)\end{array}$ & $\begin{array}{l}2.40[1.59-3.60]^{* *} \\
\mathrm{I}\end{array}$ & 0.000 \\
\hline Low intake of vegetables & $\begin{array}{l}\text { Yes } \\
\text { No }\end{array}$ & $\begin{array}{l}101(52.3) \\
67(32.2)\end{array}$ & $\begin{array}{l}92(47.7) \\
|4|(67.8)\end{array}$ & $\begin{array}{l}2.43[1.54-3.47]^{* *} \\
\mathrm{I}\end{array}$ & 0.000 \\
\hline Family history of hypertension & $\begin{array}{l}\text { Yes } \\
\text { No }\end{array}$ & $\begin{array}{l}56(63.6) \\
112(35.8)\end{array}$ & $\begin{array}{l}32(36.4) \\
20 I(64.2)\end{array}$ & $3.14[1.92-5.14]^{* *}$ & 0.000 \\
\hline
\end{tabular}

Notes: *Significant at a $p$-value of $<0.05$ and at $* * p<0.01$.

Abbreviations: COR, Crude OR; BMI, Body Mass Index.

Table 4 Multivariable logistic regression analysis of factors associated with hypertension among older adults in Chiro Town, Oromia, Ethiopia, March, 2018 ( $\mathrm{N}=40 \mathrm{I})$

\begin{tabular}{|c|c|c|c|c|c|}
\hline \multirow[t]{2}{*}{ Variables } & \multirow[t]{2}{*}{ Category } & \multicolumn{2}{|c|}{ Hypertension n (\%) } & \multirow[t]{2}{*}{ COR $(95 \% \mathrm{Cl})$} & \multirow[t]{2}{*}{ AOR $(95 \% \mathrm{Cl})$} \\
\hline & & Yes $(n=168)$ & No $(n=233)$ & & \\
\hline Age group & $\begin{array}{l}50-59 \\
60-69 \\
70+\end{array}$ & $\begin{array}{l}43(32.6) \\
52(43.0) \\
73(49.3)\end{array}$ & $\begin{array}{l}89(67.4) \\
69(57.0) \\
75(50.7)\end{array}$ & $\begin{array}{l}\text { I } \\
\text { I.56 [0.94-2.60] } \\
2.01[1.24-3.28]\end{array}$ & $\begin{array}{l}\text { I } \\
1.38[0.78-2.44] \\
1.91[1.12-3.27]^{*}\end{array}$ \\
\hline Physical activity & $\begin{array}{l}\text { Yes } \\
\text { No }\end{array}$ & $\begin{array}{l}37(32.7) \\
|3|(45.5)\end{array}$ & $\begin{array}{l}76(67.3) \\
157(54.5)\end{array}$ & $\begin{array}{l}\mathrm{I} \\
\mathrm{I} .71 \text { [1.09-2.75] }\end{array}$ & $\begin{array}{l}1 \\
1.13[0.66-1.92]\end{array}$ \\
\hline Low intake of fruits & $\begin{array}{l}\text { Yes } \\
\text { No }\end{array}$ & $\begin{array}{l}106(52.2) \\
62(31.3)\end{array}$ & $\begin{array}{l}97(47.8) \\
136(68.7)\end{array}$ & $\begin{array}{l}2.40[1.59-3.60] \\
\mathrm{I}\end{array}$ & $\begin{array}{l}2.45[1.55-3.86]^{* *} \\
1\end{array}$ \\
\hline Low intake of vegetables & $\begin{array}{l}\text { Yes } \\
\text { No }\end{array}$ & $\begin{array}{l}\text { I0I (52.3) } \\
67(32.2)\end{array}$ & $\begin{array}{l}92(47.7) \\
|4|(67.8)\end{array}$ & $\begin{array}{l}2.43[1.54-3.47 \\
\mathrm{I}\end{array}$ & $\begin{array}{l}1.38[0.52-3.61] \\
\mathrm{I}\end{array}$ \\
\hline BMI & $\begin{array}{l}\text { Normal } \\
\text { Underweight } \\
\text { Overweight/obese }\end{array}$ & $\begin{array}{l}91(33.4) \\
10(27.8) \\
67(72.0)\end{array}$ & $\begin{array}{l}|8|(66.5) \\
26(72.2) \\
26(28.0)\end{array}$ & $\begin{array}{l}\text { I } \\
0.77[0.35-1.66] \\
5.13[3.05-8.61]\end{array}$ & $\begin{array}{l}\text { I } \\
0.63[0.28-1.40] \\
4.29[2.48-7.42]^{* *}\end{array}$ \\
\hline Family history of hypertension & $\begin{array}{l}\text { Yes } \\
\text { No }\end{array}$ & $\begin{array}{l}56(63.6) \\
112(35.8)\end{array}$ & $\begin{array}{l}32(36.4) \\
20 I(64.2)\end{array}$ & $\begin{array}{l}3.14[1.92-5.14] \\
\mathrm{I}\end{array}$ & $\begin{array}{l}2.95[1.70-5.12]^{* *} \\
1\end{array}$ \\
\hline
\end{tabular}

Notes: Significant at $* p$-value of $<0.05$ and at $* * p<0.01$.

Abbreviations: AOR, Adjusted OR; BMI, Body Mass Index.

above 55 year-olds and Durame town in above 51 years which prevalences of $66.5 \%$ and $52.6 \%$ respectively. This is due to the difference in age groups of the study subjects. Both studies were conducted among the general adult population and the proportion of older adults in the samples were small $\left(37 \%\right.$ in Durame town ${ }^{15}$ and $7.5 \%$ in Bedele). ${ }^{27}$
As this result indicated, as age increases the prevalence of hypertension also increases with it. The age group of 70 years and above was almost two times more likely to be hypertensive as compared to the 50-59 years age group. As many studies agreed, studies conducted in Ethiopia: Gondar, ${ }^{14}$ Durame, ${ }^{15}$ Kenya, ${ }^{21}$ Ghana, ${ }^{25}$ Bedele, ${ }^{30}$ Zambia $^{31}$ and Taiwan $^{32}$ showed that the prevalence of hypertension was 
higher in older ages. This might be due to the fact that the biological effect of increased arterial resistance due to arterial thickening as one gets older. ${ }^{6}$

The results of this study revealed that low intake of fruits was associated with hypertension; respondents who didn't consume adequate fruit were 2.45 times more likely to be hypertensive than their counterparts. This finding is in line with studies done in Aksum, ${ }^{20}$ Addis Ababa, ${ }^{33}$ and Japan. $^{34,35}$ This could be partly explained by fruit intake reducing the risk of hypertension through weight reduction as evidenced by the finding of a study done elsewhere. ${ }^{6}$

The present study indicated that BMI was independently associated with hypertension; overweight/obese respondents were 4.29 times more likely to be hypertensive compared to their normal counterparts. This finding was in line with previous reports from population-based studies in Ethiopia: Gondar, ${ }^{14}$ Durame, ${ }^{15}$ Axum, ${ }^{20}$ and Jigjiga city. ${ }^{36}$ This finding was also in agreement with similar studies in other countries: Kenya, ${ }^{21}$ South Africa ${ }^{27}$ and Taiwan. ${ }^{32}$

In this study, having a family history of hypertension was significantly associated with being hypertensive. This finding is also similar to studies done in Gondar, ${ }^{14}$ Durame town, ${ }^{15}$ Miyun district of Beijing China, ${ }^{28}$ and Jigjiga city. ${ }^{36}$ Family history of hypertension was found to be a strong risk factor of hypertension. This could be due to the fact that family members may share similar lifestyle and genetic factors.

\section{Strengths of the study}

Conducting a complete census to get a list of all households with older adults aged 50 years and above in the town.

\section{Limitations of the study}

This study had several drawbacks. The study suffered from the usual limitations of cross-sectional studies. Since the study was in an urban population, the findings cannot be generalized to rural populations. Furthermore, this study is not free from recall and social desirability biases (selfreported factors like: age, income, tobacco, alcohol, physical activity, and self-reported DM).

\section{Conclusion}

The prevalence of hypertension among older adults was found to be high. Factors including being of older age, low fruit intake, being overweight/obese and having a family history of hypertension were found to be significantly associated with hypertension.
Close monitoring of the patients with the identified risk factors should be emphasized.

\section{Ethical statement}

Ethical clearance was obtained from the Research and Ethical Review Board of Jimma University and a permission letter was obtained from Chiro town health office, Ethiopia. We also confirm that the study was conducted in accordance with the Helsinki Declaration. Informed verbal consent was obtained from each study participant and approved by the Ethical Review Board of Jimma University. The patients were also informed for confidentiality of the information by use of codes instead of any personal identifiers.

\section{Data availability}

Data are available from the corresponding author upon reasonable request.

\section{Acknowledgment}

We are grateful to the study participants who participated into this study. This project was privately funded.

\section{Author contributions}

All authors contributed toward data analysis, drafting and critically revising the paper, gave final approval of the version to be published, and agreed to be accountable for all aspects of the work.

\section{Disclosure}

The authors declare that they have no competing interests.

\section{References}

1. World Health Organization. Non Communicable Diseases Country Profiles. Geneva: World Health Organization; September, 2011.

2. World Health Organization. A Global Brief on Hypertension Silent Killer; Global Public Health Crisis. Geneva: World Health Organization; 2013.

3. Bakris GL, Black HR, Cushman WC, et al. The seventh report of the joint national committee on prevention, detection, evaluation, and treatment high blood pressure. Bethesda: National Heart, Lung, and Blood Institute; 2004.

4. Marwiro A. Prevalence and Risk Factors for Hypertension among Bulawayo City Council Employees. Zimbabwe. Unpublished 2010.

5. Kearney PM, Whelton M, Reynolds K, Munter P, Whelton PK, He J. Global burden of hypertension: analysis of worldwide data. Lancet. 2005;365:217-223. doi:10.1016/S0140-6736(05)17741-1

6. Longo DL, Kasper DL, Jameson JL, Fauci AS, Hauser SL, Loscalzo J, editors. Harrison's Principles of Internal Medicine. 18th ed. New York: McGraw-Hill; 2012:7.

7. World Health Organization. Ghana Country Assessment Report on Ageing and Health. Geneva, Switzerland: WHO; 2014.

8. World Health Organization. Global Health Observatory (GHO) Data: Raised Blood Pressure. Geneva, Switzerland: WHO 2016. 
9. World Health Organization. Global Health RIsks; Mortality and Burden of Disease Attributable to Selected Major Risks. Geneva, Switzerland: WHO; 2009.

10. World Health Organization. World Health Statistics. Geneva, Switzerland: WHO; 2014

11. NCD Risk Factor Collaboration. Worldwide trends in blood pressure from 1975 to 2015: a pooled analysis of 1479 population-based measurement studies with $19 \cdot 1$ million participants. Lancet. 2016. doi:10.1016/s0140-6736(16)31919-5

12. Kandala N, Uthman OA. Prevalence of hypertension in low- and a systematic review and meta-analysis. Medicine. 2015;94(50):1-16. doi:10.1097/MD.0000000000000874

13. Adeloye D, Basquill C, Schnabel RB. Estimating the prevalence and awareness rates of hypertension in Africa : a systematic analysis. PLoS One. 2014;9(8):e104300. doi:10.1371/journal.pone.0104300

14. Awoke A, Awoke T, Alemu S, Megabiaw B. Prevalence, and associated factors of hypertension among adults in Gondar, Northwest Ethiopia. BMC Cardiovasc Disord. 2012;12(1):16. Available from: http://www.biomedcentral.com/1471-2261/12/113.

15. Helelo TP, Gelaw YA, Adane AA, Fuchs FD. Prevalence and associated factors of hypertension among adults in Durame Town, Southern Ethiopia. PLoS One. 2014;9(11):e112790. doi:10.1371/journal.pone. 0112790

16. Lloyd-sherlock P, Beard J, Minicuci N, Ebrahim S, Chatterji S. Hypertension among older adults in low and middle-income countries: prevalence, awareness and control. Int $J$ Epidemiol. 2014;43:116-128. doi:10.1093/ije/dyu034

17. World Health Organization. Global Recommendations on Physical Activity for Health. Geneva: World Health Organization; 2010.

18. Addo J, Agyemang C, Smeeth L. A review of population-based studies on hypertension in Ghana. Ghana Med J. 2012;46(2 Suppl):4-11.

19. Manandhar K, Koju R, Sinha NP, Humagain S. Prevalence and associated risk factors of hypertension among people aged 50 years and more in Banepa municipality Nepal. Kathmandu Univ Med J. 2012;39(3):35-38.

20. Gebrihet TA, Mesgna KH, Gebregiorgis YS, et al. Awareness, treatment, and control of hypertension is low among adults in Aksum town, northern Ethiopia : a sequential quantitative-qualitative study. PLoS One. 2017;12(5):1-16. doi:10.1371/journal.pone.0176904

21. Joshi MD, Ayah R, Njau EK, et al. Prevalence of hypertension and associated cardiovascular risk factors in an urban slum in Nairobi, Kenya : a population-based survey. BMC Public Health. 2014;14:1177. doi:10.1186/1471-2458-14-1177

22. National Heart Lung and Blood Institute. What Is the DASH Eating Plan. Bethesda: NIH Publication; 2014.

23. World Health Organization. WHO STEPwise Approach to Chronic Disease Risk Factor Surveillance (STEPS). Geneva, Switzerland: WHO; 2005.
24. Teferra S, Medhin G, Selamu M, Bhana A, Hanlon C, Fekadu A. Hazardous alcohol use and associated factors in a rural Ethiopian district: a cross-sectional community survey. BMC Public Health. [Internet]. 2016;1-7. doi:10.1186/s12889-016-2911-6

25. Solomon I, Adjuik M, Takramah W, et al. The frequency of hypertension and pre-hypertension among adults in the Hohoe municipality of Ghana. J Prev Med Health. 2017;1(3):1010.

26. Sheth AM, Jadav PA. Prevalence and factors affecting hypertension among old age population in rural area. Int J Community Med Public Health. 2016;3:1866-1871. doi:10.18203/2394-6040.

27. Peltzer K, Phaswana-mafuya N. Hypertension and associated factors in older adults in South Africa. Cardiovasc J Afr. 2013;24(3):66-71. doi:10.5830/CVJA-2013-002

28. Forouzanfar MH, Liu P, Roth GA, et al. Global burden of hypertension and systolic blood pressure of at least 110 to $115 \mathrm{~mm} \mathrm{Hg}, 1990$ 2015. JAMA. 2017;317(2):165-182. doi:10.1001/jama.2016.19043

29. Mendes TA, Goldbaum M, Segri NJ, et al. Factors associated with the prevalence of hypertension and control practices among elderly residents of Sao Paulo city, Brazil. Cad Saude Publica. 2013;29:22752286. doi:10.1590/0102-311x00151312

30. Bonsa F, Gudina EK, Hajito KW. Prevalence of hypertension and associated factors in Bedele town, Southwest Ethiopia. Ethiop $J$ Health Sci. 2014;24(1):21-26.

31. Goma FM, Nzala SH, Babaniyi O, et al. Prevalence of hypertension and its correlates in Lusaka urban district of Zambia: a population based survey. Int Arch Med. [Internet]. 2011; 4(1):34 Available from: http://www.intarchmed.com/content/4/1/34.

32. Tsai AC, Liou JCM. Interview to study the determinants of hypertension in older adults in Taiwan : a population based cross- sectional survey. Asia Pac J Clin Nutr. 2017;16(2):338-345.

33. Getachew F, Dirar A, Solomon D. Prevalence of undiagnosed hypertension and associated factors among residents in Gulele Sub-City, Addis Ababa, Ethiopia. J Community Med Health Educ. 2018;8:590. doi:10.4172/2161-0711.1000590

34. Tsubota-Utsugi M, Ohkubo T, Kikuya M, et al. High fruit intake is associated with a lower risk of future hypertension determined by home blood pressure measurement: the OHASAMA study. J Hum Hypertens. [Internet]. 2011;25(164 \pm 71$)$. PMID: 20445569. doi:.10. $1038 /$ jhh. 2010.48

35. Utsugi MT, Ohkubo T, Kikuya M, et al. Fruit and vegetable consumption and the risk of hypertension determined by self-measurement of blood pressure at home: the Ohasama study. Hypertens Res. 2008;31:1435 \pm 43 .

36. Asresahegn H, Tadesse F, Beyene E. Prevalence and associated factors of hypertension among adults in Ethiopia: a community based cross-sectional study. BMC Res Notes. [Internet]. 2017;1-8. doi:10.1186/s13104-017-2966-1
Integrated Blood Pressure Control

\section{Publish your work in this journal}

Integrated Blood Pressure Control is an international, peer-reviewed open-access journal focusing on the integrated approach to managing hypertension and risk reduction. Treating the patient and comorbidities together with diet and lifestyle modification and optimizing healthcare resources through a multidisciplinary team approach constitute key features of the journal. This journal is indexed on
American Chemical Society's Chemical Abstracts Service (CAS) The manuscript management system is completely online and includes a very quick and fair peer-review system, which is all easy to use. Visit http://www.dovepress.com/testimonials.php to read real quotes from published authors. 